\title{
Recuerdos, emoción, representación. Formas de la memoria de la represión en la España actual
}

\author{
Memories, Emotion, Representation. \\ Forms of the Memory of Repression in present day Spain
}

\author{
Pedro Piedras Monroy \\ Investigador independiente \\ pedropiedras@hotmail.com
}

\begin{abstract}
History has got the monopoly of legitimate representation of the past, above all due to its privileged academic position. Its accounts operate as true and valid and often label all the rest as fiction. There are nevertheless some other forms, linked to memory, capable of learning from and narrating through emotions, opening paths of understanding, compromise and intervention in society. Referred to the memory of repression in Spain, we talk in this article about graphic novel, photography and documentary films.
\end{abstract}

Keywords: Francoist repression, Representation, Memory, Graphic Novel, Photography, Documentary films

La historia como discurso cientifico ha servido para estudiar causas y consecuencias de esa constelación de conflictos denominada con el concepto-tótem de Guerra Civil Española; también para contextualizar y darle un sentido a los acontecimientos de la misma, registrar atrocidades y tratar de servirlas de forma aséptica comme il faut. ${ }^{1}$

La historia seria renuncia al nexo sentimental con el presente aunque no suele hacer ascos a que su explicación se contemple como redención. La suficiencia con la

\footnotetext{
${ }^{1} \mathrm{El}$ sesgo militante ha sido denunciado con frecuencia (véase Loureiro, 2008, pp. 24-25).
} 
que ha dominado el relato del pasado y su monopolio de facto del discurso legítimo sobre el mismo oculta no obstante que, a menudo, ha quedado lejos de su alcance una indagación profunda en las raíces de los acontecimientos. Algo como lo que hace Michael Haneke en La cinta blanca - buscar las causas íntimas del horrorqueda al margen de las posibilidades expresivas de la historia, aunque para los historiadores esa obra no sea quizá más que otra ficción cargada de emocionalismo y, por tanto, alejada de la "verdad".

La historia se jacta de que hace tiempo ya que todas las respuestas están dadas (Casanova, 2006), pero la maldad de unos generales, las contradicciones socioeconómicas, la dureza del enfrentamiento ideológico, el contexto internacional o la locura colectiva empiezan a resultar insuficientes como explicaciones del conflicto civil en España; demasiado materiales, demasiado lineales para la magnitud y la complejidad del fenómeno y sus consecuencias.

Mientras tanto, una pregunta tan simple y esencial como: “¿Dónde se escondía en España tanta crueldad?"2 no ha encontrado aún una respuesta satisfactoria; ello nos deja inermes ante otras aún más inquietantes: "¿Sigue escondiendo nuestro presente esa misma crueldad?". Si algo parece indiscutible es que la omnipresente historia no solo no ha sido capaz de identificar las causas profundas de la lucha entre los españoles antes y ahora sino tampoco de contribuir a la superación del trauma de la represión y de la guerra, a la creación de una memoria colectiva democrática ni a la definitiva victoria sobre el franquismo. Ni siquiera ha generado un consenso real sobre lo negativo del franquismo. Es probable que — no sin razón - algún historiador responda que la historia no está para esas cosas..., para ser "útil" en ese sentido ético y político, sino tan solo para fijar hechos. ¿Habrá que entender que esa tarea les corresponde a otros? Pero, ¿a quiénes? ¿A los pedagogos? ¿A los psicólogos? ¿A los sociólogos? ¿A los politólogos? ¿A los juristas?

Ante esa indefinición, parece lógico convenir que alguna forma habrá de encontrarse para mirar al pasado de ese modo "útil".

Todo pasado acucia e interpela al presente pero, con mayor motivo, el pasado cercano que mantiene un denso vínculo emocional con el ahora. Representar - como hace la historia - el pasado cercano despegado de su fuerte componente emocional implicará dilapidar buena parte de las posibilidades para comunicarlo. La situación será más aguda cuando lo que se confronta es un pasado cargado de horror, cuyos relatos generan una extraordinaria corriente de emociones incontrolables, inaceptables desde la disciplina histórica. Dar cuenta del pasado traumático implica ser conscientes con Sartre de que "la emoción es una determinada manera de

\footnotetext{
${ }^{2} \mathrm{He}$ tomado prestada esta pregunta a Svetlana Alexievich, quien la formula referida al mundo soviético y postsoviético (2015, p. 325). Paralelamente, Haneke enuncia su pregunta fundamental como: “¿Por qué existe esta forma de radicalismo precisamente en Alemania?” (Haneke, 2010, p. 157).
} 
aprehender el mundo" (Sartre, s.f., p. 19) y no se podrá dejar de lado sin más el aspecto emocional si no se quiere errar en las conclusiones y fracasar en su comunicación.

José Carlos Bermejo Barrera plantea el emocional como uno de los grandes déficits del discurso histórico:

Las prostitutas y las mujeres violadas por los soldados son, como el miedo, el odio, la ira, los cuerpos destrozados y mutilados, los cadáveres de los soldados y civiles, parte esencial de la guerra real, la que no ven los altos mandos, ni los políticos, ni los historiadores y los practicantes de la retórica de la guerra. La guerra tiene colores, olores y sensaciones, y sobre todo pasiones y sentimientos, dolores y sufrimientos. Pero nada de ello aparece en la guerra abstracta ni en la guerra de la mayor parte de los historiadores que juegan a ser generales sobre un mapa o con su ordenador, sin tener en muchos casos no sólo ninguna experiencia concreta de la guerra, sino tampoco ningún conocimiento técnico de la misma. Y es que para ellos la guerra es un espectáculo, una visión global, como un paisaje con batalla que intentan evocar leyendo o transcribiendo a veces unos textos de otros narradores que tampoco vivieron ni recogieron la guerra real, sino que se quedaron con la guerra abstracta: la que no huele ni mancha, y la que permite al historiador sentirse seguro, amparado y como parte de un discurso que la justifica junto con el resto del orden social y político existente.

Para esos historiadores la guerra es un artificio entre otros en sus visiones de la totalidad desde las que no quieren ver ni a lo lejos los sufrimientos de los demás. [...] el sufrimiento y las víctimas le son incómodos a los historiadores si no pueden rentabilizarlos para sus fines políticos. Y por eso muchos de ellos niegan el valor de los relatos de las víctimas de la guerra y la historia cuando éstas quieren tener su voz y narrar, aunque sea mal, su historia.

A los historiadores [...] no les interesa el dolor más que como excusa para condenar o alabar algo, porque el dolor rompe la unidad de su visión y de su relato, haciendo saltar sus límites y corriendo el peligro de colocarlos al borde de un abismo [... ${ }^{3}$

El estudio de las emociones (Emotionsforschung) ${ }^{4}$ nos aboca al esfuerzo teórico de analizar lo emocional a la hora de construir los relatos sobre el pasado y a buscar una forma adecuada para servir unos relatos que, en buena medida, serán aprehendidos emocionalmente. En ese sentido, habrá que incorporar al relato del pasado otros lenguajes que faciliten el tráfico emocional pasado-presente, pese a que buena parte de esos relatos no se consideren representaciones legítimas desde la óptica académica por carecer del sello de lo científico y estar demasiado vinculados a las problemáticas de la memoria.

\footnotetext{
${ }^{3}$ Extractos de Bermejo Barrera "Historiadores, espectadores y víctimas. El discurso histórico como artificio" (en prensa).

${ }^{4}$ Muy interesantes, en ese sentido, resultan los trabajos introductorios de Jenefer Robinson (2009) y Gesine L. Schiewer (2014).
} 
Por todo ello, a continuación reflexionaremos sobre algunos ejemplos que no se construyen como relatos históricos y que, sin embargo, dan cuenta de aspectos decisivos del pasado; pertenecerán a la novela gráfica, la fotografía y el cine documental. No incluiré la Nueva Memoria Textual (NMT), por haber sido objeto de análisis en una publicación reciente (Piedras Monroy, 2014, pp. 48-50); tampoco, la novela ni la cinematografía convencionales, por ser territorios más conocidos y que desbordarían las dimensiones de este trabajo.

\section{LA NOVELA GRÁFICA}

Desde la aparición de Maus de Art Spiegelman (1980-1991) o Pies Descalzos de Keiji Nakazawa (1973-2008), la novela gráfica ha demostrado una enorme potencia para indagar en cuestiones relacionadas con la memoria traumática. En el caso español, entre las más relevantes señalaremos, en primer lugar, el díptico El arte de volar (2010) y El ala rota (2016) de Antonio Altarriba y Kim, que revisa el siglo $\mathrm{XX}$ desde las biografías del padre y de la madre del guionista.

Los ritmos y los tiempos de la memoria del padre en El arte de volar no coinciden con los de la historiografía y la tragedia que encarna no acaba de encajar en el relato histórico: toda la vida del protagonista se describe como una caída. Cada capítulo se abre con una imagen del piso correspondiente — cada vez más bajode la caída del padre en su suicidio desde la $3 .{ }^{a}$ planta de una residencia de ancianos... una imagen imponente de la búsqueda de las causas profundas: la vida horrible y violenta en su pueblo, la guerra, el exilio, la vuelta a la corrupta España franquista y la fase final en la residencia. Con su retorno a España, Antonio asume su imposibilidad de volar (ser libre) y morirá ya en el siglo XXI pero con la misma sensación de falta de libertad, pues el relato carece del periodo fundante de la Transición. De hecho, la historia vehiculada por el yo del padre no coincide ni con la historia oficial ni con sus interpretaciones.

Algo semejante ocurrirá en El ala rota. Petra, la madre del autor, que aparece en $\mathrm{El}$ arte de volar como un elemento subsidiario, antipático, beato y gris, del que apenas conocemos su frigidez, su insensibilidad y su cerrilidad, en contraste con la riqueza del pensamiento de su marido, se convertirá en el centro de esta obra conmovedora, que penetra en un núcleo oscuro apenas hollado por el arte: el laberinto social y psicológico de las mujeres españolas de clase baja en el siglo XX. A nadie se le escapa que se trata de una imagen femenina proyectada por un hombre; $\mathrm{y}$, sin embargo, la agudeza y la convicción de guionista y dibujante hacen de esta historia un jalón imprescindible del feminismo gráfico. 
El "ala rota" de Petra es su brazo izquierdo, atrofiado desde el mismo día de su nacimiento por culpa —otra vez - de la violencia masculina, pero cuya importancia ella había sabido ocultar sin queja. Ya desde la primera escena, en la que Petra, ya anciana, agoniza en el hospital, se muestra a los ojos atónitos del lector que ni su hijo ni su marido habían conocido el estado del brazo de la madre. La mujer, oculta bajo los ropajes eternos de ama de casa y madre ejemplar, es un ser invisible (jtransparente!), indigno de atención y sin aventura. Nadie ha considerado sus problemas ni sus razones; nadie le ha preguntado nada ni se ha cuestionado el porqué de algunas de sus reacciones... a nadie parece haberle interesado lo suficiente... ni siquiera a quienes más la querían.

El "ala rota", de este modo, se convierte en un símbolo que sirve como palanca de denuncia, no solo de la situación de oclusión de las mujeres humildes en la vida real sino también de su oclusión en los relatos construidos desde una literatura y un pensamiento profundamente "machocéntricos".

Al igual que en El arte de volar, tampoco aquí existe transición política alguna... los personajes arrastran su difícil existencia por una tierra baldía a ambos lados de la muerte del dictador. La eliminación de la Transición del discurso de estas dos novelas evidencia que la historia oficial ha sobredimensionado el significado histórico de una época y sus actores, mientras las historias de la gente poco relevante pasaron por ella como por un continuum homogéneo y vacío. La historia de la "redención" democrática es "gran historia", una versión por definición impostada, interesada y manipulada por el poder y por sus aparatos publicitarios académicos. Las historias de dolor íntimo son contadas, en cambio, sotto voce por parte de aquellos que saben guardar una saludable distancia respecto de sí mismos.

Otro autor clave de la novela gráfica en España, Paco Roca, ha indagado como pocos en cuestiones relacionadas con la memoria en un sentido amplio, como demuestra su célebre Arrugas (2007). No obstante, la obra más interesante para nosotros será Los surcos del azar (2013), que no se limita a revisar la memoria de los republicanos exiliados sino que aporta una original perspectiva narrativa y teórica. $\mathrm{Al}$ autor le preocupa mostrar el proceso de excavación mental que supone el acceso al recuerdo atesorado en la mente de un testigo.

En Los surcos del azar, el yo-sujeto del narrador vuelve a situarse en el centro del relato. Así, un Paco Roca-personaje acude al encuentro de un octogenario republicano que combatió en la II Guerra Mundial y que desapareció misteriosamente en una misión en 1944. Miguel es un viejo exiliado que había formado parte de la IX compañía de la 2. ${ }^{\text {a }}$ división blindada del ejército de la Francia libre ( a Nueve), que participó en la liberación de París y que ahora vivía en una pequeña ciudad francesa. Superando las primeras reticencias, el Roca-personaje se gana la confianza del viejo y entre ellos se dibuja una relación trenzada por la experiencia del contar. Al hilo de la historia, el Roca-autor va describiendo en imágenes la aciaga y, a la vez, increíble hazaña de los españoles de La Nueve, desde su agónica 
salida del puerto de Alicante y su cautiverio en el norte de África hasta su ingreso en el ejército de Leclerc y su definitiva entrada en París.

Ahora bien, será el relato del viejo — personaje en absoluto embellecido, cargado de resentimiento - el que arroje verosimilitud y certidumbre, el que nos infunda confianza. Frente a la escritura "científica" y aséptica de la historia, la memoria inscrita en Los surcos del azar no apela solo a una borrosa verdad sino también al conocimiento que fluye a través de la experiencia y el sentimiento, por definición ajenos al relato histórico. La descripción de los suicidios en el puerto de Alicante o la escena última de Machado sentado junto a su madre entre las filas de refugiados... le impactan al lector como un verso y le narran un pasado en el que perduran un horror, un sufrimiento y una ternura imposibles de percibir desde el frío rigor de la historia académica.

El impacto inusitado de Los surcos del azar ha desembocado en un enorme interés por La Nueve, por el Stanbrook (último buque que salió de España con refugiados), por los bombardeos del puerto de Alicante... Todo ello redunda en la importancia que adquiere la forma de la narración y su dimensión emocional a la hora de intervenir en la sociedad.

\section{LA FOTOGRAFÍA}

Desde sus orígenes, la fotografía ha tratado de hacer patente lo invisible, de captar lo efímero y de descubrir lo inadvertido, aquello que el movimiento de lo real nos impide ver. La memoria y la presencia de la represión han encontrado por ello un amplio espacio de reflexión en los relatos fotográficos, como puede comprobarse en Aitor Fernández y su trabajo en Vencidxs, donde en paralelo a los testimonios de víctimas del franquismo aparecen retratos e imágenes de miradas y manos de testigos, a modo de expresión visual emocional que complementa a los textos en el sentido de lo planteado por Didi-Huberman, cuando afirma que "en cada acto de memoria $[\ldots]$ el lenguaje y la imagen $[\ldots]$ son absolutamente solidarios y no dejan de intercambiar sus carencias recíprocas: una imagen acude allí donde parece fallar la palabra; a menudo, una palabra acude allí donde parece fallar la imaginación" (Didi-Huberman, 2004, p. 49).

Otro formidable ejemplo es el del fotógrafo Sergi Bernal, que acudió a la fosa común de La Pedraja (Villafranca de Montes de Oca, Burgos) con la intención de registrar con su cámara todas las fases de exhumación de una fosa de la represión. En los días que pasó a pie de fosa, vio cómo sus expectativas fueron rotando desde los trabajos de desenterramiento hacia el universo que se movía en torno a ellos y, en especial, hacia los familiares. Francisco Ferrándiz, presente en la exhumación, describirá así la presencia del fotógrafo: 
Más allá del equipo, que era el habitual en muchas de las excavaciones de verano de gran envergadura que lleva a cabo Aranzadi, la exhumación de La Pedraja era singular por la presencia del fotógrafo Sergi Bernal, que, deslizando su mirada entre los protocolos técnicos, las historias de los familiares y los propios objetos y restos que emergían de la fosa, construyó allí un mundo fotográfico paralelo, en blanco y negro, desde el que dio vida al proyecto Desenterrando el silencio. (Escribano, et al., 2012, p. 88)

A pie de fosa y casi al tiempo, fotógrafo y antropólogo descubrieron la existencia del maestro republicano asesinado Antoni Benaiges, cuya historia acabaría convirtiéndose en el hilo conductor del discurso de Bernal, que publicará su imponente serie de fotos en las páginas de Antoni Benaiges, el maestro que prometió el mar (2012).

Exhumaciones, huesos de cuerpos yacentes en la tierra, arqueólogos que trabajan sobre ellos, familiares que rodean la fosa, en grupos, conversando, pensativos, ofreciendo su testimonio, mirando, señalando a su pariente o viendo la propia exposición de fotografías "Desenterrando el silencio", poniendo flores en el monolito, llevando cajas con restos... Bernal establece un genuino flujo emocional que vincula el pasado que surge de la tierra en forma de huesos y las miradas, que se transforman en emociones y recuerdos, en historias y otra vez en nuevos sentimientos y en nuevas miradas. Pocas artes son capaces de transmitir un conjunto tan complejo de sensaciones o de explicitar sin palabras la complejidad del encuentro de los familiares con la evidencia material del horror. Como Cartier-Bresson, Bernal capta el momento decisivo, "el momento en el que, por un instante sumamente corto, se encuentran en equilibrio todos los agitados elementos del motivo" (Koetzle, 2007, p. 83); traduce los mundos visuales de autores como Arno Fischer o Robert Frank a un relato denso y humano sobre la naturaleza de la vivencia actual del horror del pasado.

Entre los trabajos de Sergi Bernal, destaca no obstante una foto-tapiz de la fosa 1 a tamaño natural, que suele exhibirse desplegada sobre el suelo, dando la sensación de ser la propia fosa original. La fotografía aquí se transfigura en lugar, un lugar que ha de ser bordeado para verlo; en ocasiones, se ponen conos o cinta de tráfico para evitar el acceso al mismo. La fotografía de pronto se muta en escenografía, no ya del horror sino del testimonio del horror.

\section{EL CINE DOCUMENTAL}

El género documental ha sido con mucho el que más ampliamente se ha dedicado a tratar la problemática que nos ocupa; en ocasiones con piezas tan conmovedoras como La memoria recobrada de Alfonso Domingo. En todo caso, la estructura de estos documentales — que recuerda a la de España en Guerra, ${ }^{5}$ a su vez inspirada

\footnotetext{
${ }^{5}$ Curiosamente, en la cubierta de la edición en 15 DVDs, el reclamo consiste en etiquetarla como "Memoria histórica".
} 
en la narración de El Mundo en Guerra, emitida entre 1973 y 1974 - tiende a ser siempre la misma. Un relato histórico vehiculado por una voz en off avanza apoyado por intervenciones de historiadores, testigos e imágenes de archivo. Este tipo de documental, en absoluto exento de valor, tiene en cambio una composición apegada en exceso al relato histórico en detrimento de la búsqueda de otras posibilidades expresivas. Por ello, fijaremos la mirada en otro tipo de documentales, como los que representan El retratista de Alberto Bougleux y Sergi Bernal y Llach: la revolta permanent de Lluís Danés.

La aludida historia del maestro Benaiges dio pie a la construcción de un documental, El retratista, donde se muestra la profundidad del contenido de cada nombre propio, en apariencia vacío. El nombre de Antoni Benaiges, cuya presencia resultaba inexplicable en unos cuadernillos procedentes de una imprenta escolar mexicana del método Freinet, empieza a cobrar sentido desvelando una historia de represión masiva y exilio. El drama de la historia no reside, sin embargo, solo en el asesinato del maestro sino en el viaje truncado de los niños del pueblo burgalés de Bañuelos de Bureba a ver el mar, epítome de una generación de españoles a la que se negó el acceso al conocimiento. Maestros y niños de una escuela Freinet de México fundada por compañeros exiliados de Benaiges, testimonios de ancianos de Bañuelos, historias infantiles impresas en cuadernos, viejas fotos de un joven maestro... El retratista da dimensión al hueco oculto tras cada nombre de la represión. En la emoción inusitada de los testimonios, asistimos a las irradiaciones que genera ese nombre, vislumbramos el destino de tantos maestros republicanos pero también la potencia de la educación como esfuerzo universal y el valor del compromiso individual como garante de la pervivencia de lo humano.

Llach: la revolta permanent dirigida por Lluís Danés, con guion de Lluís Arcarazo y Lila Pla Alemany ofrece una particular visión de la masacre perpetrada en Vitoria el 3 de marzo de 1976 por la policía franquista. En ella, no solo se indaga en la monstruosa acción represiva, en sus consecuencias y en su presencia actual en víctimas y familias, sino que, en paralelo, se construye una secuencia vital personal del poeta y cantautor Lluís Llach. Las líneas "histórica" y biográfica convergen en el acto de homenaje a las víctimas de la masacre con la interpretación de Campanades a morts, la obra creada por Llach a partir del terrible impacto que le causó su experiencia con el horror de aquel acontecimiento.

Frente a la posibilidad de una narración plana (historicista) de los acontecimientos, en el documental late un relato mediado por la presencia de un "yo": el de Lluís Llach que, al hilo de su propia historia, narra el horror. La descripción de los acontecimientos de Vitoria sirve para orientar al espectador y ahorrarle la confusión de que sea el propio Llach quien cuente a la vez su vida y el episodio represivo. La forma de narrar en dos líneas (la de la masacre y la de la vida del autor) permite hacer comprensible la explicación que este ofrece de sí mismo y de su encuentro con el horror. 
El título del documental resulta del todo elocuente para entender lo que este pretende: el centro del mismo es Llach y no la masacre de Vitoria. Sin embargo, Llach aparece seguido de dos puntos que parecen abrir paso a una explicación de sí mismo. Llach es la revuelta permanente, de acentos troskianos.

Desde el mismo título se trata de desarticular uno de los elementos constitutivos del nombre propio: su carencia de significado. ${ }^{6}$ La vida de Lluís Llach se identifica como una revuelta permanente $\mathrm{y}$, entre otros episodios que le llevaron una y otra vez a indignarse y levantarse, los acontecimientos de Vitoria simbolizan su sensibilidad reactiva, su compromiso y, en definitiva, su "yo".

Por otro lado, el documental nos plantea diversas líneas en las que incide la experiencia del horror en el individuo y el modo en el que ese horror se encastra en la identidad a través de la memoria. El concierto del 2006, en el que se homenajea a las víctimas y se denuncia el olvido, se convierte en un acto de rememoración no ya para la comunidad que padeció el horror de la masacre sino también para el individuo cuya identidad se ha construido a partir de su implicación. Lluís Danés ha explicitado la transición entre el "yo" y la memoria traumática a partir de una construcción en la que el flujo emocional de Llach parece empaparse de los flujos emocionales de los testigos y familiares de las víctimas de la masacre. Con ello, no solamente "cuenta" lo ocurrido (en buena medida a partir de documentos visuales y sonoros) sino también los reflejos de lo ocurrido (vivencias individuales de testigos y familiares, que aportan memorias parciales) en la creación audiovisual del documental. En esta construcción, al igual que en El retratista, no aparecen historiadores porque el director no ha querido incluir discursos mediados sino la crudeza del testimonio y la potencia del recuerdo. Aquí nadie tiene en la manga el as de ninguna verdad incontestable.

En Llach: la revolta permanent, la memoria adquiere el sesgo de la reivindicación y de la intervención en la sociedad a través de la forma. La memoria activa de Llach, una memoria no histórica ni historiográfica, se erige en traza indeleble del acontecimiento que denuncia: su vida, su obra (en especial, Campanades a morts), su reactualización de la memoria (el concierto en Vitoria de 2006) y el documental que trata de todo ello se convierten en un discurso polifónico que habla del pasado traumático desde las evidencias documentales, desde las memorias emocionales de los individuos y desde la reconstrucción de una obra que no puede formularse como ciencia.

\section{III}

El relato histórico es una forma institucionalizada de acercamiento al pasado que, a menudo se muestra insuficiente para aprehenderlo, en particular, cuando se

\footnotetext{
${ }^{6}$ Véase Bermejo Barrera (2011, pp. 39-40). Una forma tópica de presentar biografías es separar el nombre propio de su lema mediante comas o puntos: Spinoza, el marrano de la razón o Julio Camba. El solitario del Palace, pero rara vez mediante dos puntos, que ante todo refuerzan la idea de definición.
} 
trata de un pasado traumático. Los Estados invierten grandes sumas de dinero en financiar una academia de historiadores profesionales que proponen su relato como el único legítimo, perpetuando así su dominio académico. Sin embargo, la historiografía ha renunciado desde hace mucho a repensarse y transformar su forma de contar, tal vez por tener una visión limitada de qué es aquello de lo que tiene que dar cuenta. Su renuncia a las emociones y los sentimientos la aleja de la sociedad para la que escribe y la lastra a la hora de dar cuenta de los acontecimientos del pasado y de implicar al público en su relato.

José Carlos Bermejo señala que:

Lo que nos recuerdan estos narradores no historiadores [...] es que el discurso de la historia como relato y discurso global puede convertirse en un artificio vacío. El historiador no puede describir lo que no ve ni vio, no puede tener la visión panorámica del mundo que le correspondía a los viejos y nuevos dioses. Sólo dispone de restos, de fragmentos materiales del pasado, sólo puede intentar hacer reconstrucciones parciales del mismo, dependiendo de su información, de sus técnicas, métodos, ideas e incluso prejuicios. El historiador es un autor como todos los demás, aunque casi siempre es mediocre en su expresión. No tiene sentido negarlo si no es para esconder la propia mediocridad tras un telón de una supuesta objetividad que no es más que el eco vacío de unas normas académicas que intentan poner a la historia al servicio de una serie de ideas, principios políticos o prejuicios de todo tipo que se cuelan por la ventana de un castillo protegido por el inmenso foso de la supuesta distancia que se dice proporciona la ciencia. (en prensa)

El relato del pasado (en particular, del pasado traumático) ha de descentralizarse, eliminando el privilegio institucional que se le concede a la disciplina histórica o, al menos, haciendo partícipe de él a otras formas narrativas como las que hemos esbozado en estas páginas. 


\section{BIBLIOGRAFÍA}

Alexiévich, S. (2015). El fin del "Homo sovieticus". Barcelona: Acantilado.

Altarriba, A. \& Kim (2009). El arte de volar. Alicante: Edicions de Ponent.

- (2016). El ala rota. Barcelona: Norma.

Bermejo Barrera, J. C. (2011). Los limites del lenguaje. Proposiciones y categorías, Madrid: Akal.

- (en prensa). "Historiadores, espectadores y víctimas. El discurso histórico como artificio". En Historia y melancolía. Madrid: Akal.

Bougleux, A. \& Bernal, S. (2014). El retratista. Barcelona: Art Blume S.L.

Casanova, J., (2006, 14 septiembre). "Sin archivos no hay historia". El País. Recogido en: http://elpais.com/diario/2006/09/14/opinion/1158184805_850215.html

Cervera, P. (1986). España en guerra (1936-1939) [Vídeo]. Madrid: RTVE. Ed. remasterizada (2010), Emon/ Planeta.

Danés, Ll. (2008). Llach: la revolta permanent [Vídeo]. Barcelona: Público.

Didi-Huberman, G. (2004). Imágenes pese a todo. Memoria visual del Holocausto. Barcelona: Paidós.

Domingo, A. (2006). La memoria recobrada. Madrid: RTVE.

Escribano, F., Ferrándiz, F. \& Solé, Q. (2012). [Desenterrando el silencio] Antoni Benaiges, el maestro que prometió el mar. [Barcelona:] Art Blume S. L./ Ventall Edicions.

Fernández, A. (2013). Vencidxs, s. 1.: Datecuenta.

Ferrándiz, F. (2014). El pasado bajo tierra. Exhumaciones contemporáneas de la Guerra Civil. Barcelona: Anthropos.

Haneke, M. (2009). La cinta blanca [Vídeo]. Cameo Media (Cameo El País, 2010).

- (2010). Gespräche mit Thomas Assheuer. Berlín: Alexander Verlag.

Koetzle, H.-M. (2007). Diccionario de fotógrafos del siglo veinte. Madrid: CBA.

Loureiro, Á. G. (2008). "Argumentos patéticos. Historia y memoria de la Guerra Civil". Claves de Razón Práctica, 186, 18-25.

Nakazawa, K. (2015). Pies descalzos. Madrid: De Bolsillo.

Piedras Monroy, P. (2014). "Hacia una redescripción textual de la memoria". Historiografias, 8, 28-56. Recogido en: http://www.unizar.es/historiografias/numeros/8/piedras.pdf

Robinson, J. (2009). Deeper than Reason. Emotion and its Role in Literature, Music and Art. New York: Oxford University Press.

Roca, P. (2013). Los surcos del azar. Bilbao: Astiberri.

Sartre, J. P. (s. f. [1939]). Bosquejo de una teoría de las emociones. Weblioteca del pensamiento. Recogido en: http://www.elseminario.com.ar/biblioteca/Sartre_Bosquejo_Teoria_Emociones.pdf (31 agosto 2016).

Schiewer, G. L. (2014). Studienbuch Emotionsforschung. Theorien - Anwendungsfelder - Perspektiven. Darmstadt: WBG.

Spiegelman, A. (2007). Maus. Madrid: Random House. 